\title{
3D Fractal Investigation on Ultrasonic Vibration Assisted End Grinding Surface of SiCp/Al Composites
}

\author{
Wei Zheng ${ }^{1, \text { a }}$, Ming Zhou ${ }^{2}$ and Li Zhou ${ }^{3}$ \\ School of Mechanical and Electrical Engineering, Harbin Institute of Technology, Harbin, 150001, PR China \\ ${ }^{1}$ zhengwhit@gmail.com, ${ }^{2}$ zhouming@hit.edu.cn, ${ }^{3}$ zhoulihit@163.com
}

\begin{abstract}
This paper presents a 3D fractal investigation on ultrasonic vibration assisted end grinding surface of $\mathrm{SiCp} / \mathrm{Al}$ composites. According to variational method, 3D surface fractal dimension is calculated with MATLAB software based on profile data, and evaluates the influence of process parameters on the surface quality. The experimental results indicate that 3D surface fractal dimension increases with spindle speed and vibration amplitude, and decreases with feedrate and cutting depth. A large value of 3D surface fractal dimension corresponds to a better surface finish.
\end{abstract}

\section{Introduction}

Superior properties such as high specific strength and specific stiffness make $\mathrm{SiCp} / \mathrm{Al}$ composites highly competitive against conventional materials and are widely used in aerospace, automobile and other fields. However, the addition of $\mathrm{SiC}$ particles makes $\mathrm{SiCp} / \mathrm{Al}$ composites hard to be manufactured because of its extreme abrasive properties. This has limited the practical application of $\mathrm{SiCp} / \mathrm{Al}$ composites, and a fair assessment of the machinability of MMCs is still a difficult issue [1]. Therefore, it is necessary to develop non-traditional machining process to meet the demand of $\mathrm{SiCp} / \mathrm{Al}$ composites machining. Ultrasonic vibration assisted end grinding is a combination of two ordinary material remove processes, i.e. grinding and ultrasonic machining during which ultrasonic vibration is applied to the cutting tool, as shown in Fig. 1 [2]. Compared with other traditional machining methods, this machining method has many advantages, such as lower grinding force, higher surface quality, higher machining efficiency and longer tool life. Fig. 2 shows the motion trajectory of a single grain in end surface of the grinding tool.

Surface topography can be characterized using an excessive number of statistical parameters depicting various aspects of the surface lay, roughness, waviness and the form. Unfortunately, many of them strongly depend on how they are actually measured, including for instance the sampling and the scan lengths, and the instrumental resolution. The machining of $\mathrm{SiCp} / \mathrm{Al}$ composites has been extensively studied experimentally and numerically to assess surface integrity. In general, based on available references, most of them focus on turning and the analysis of surface integrity is using $2 \mathrm{D}$ or 3D surface roughness [3-11].

Several research results show that the surface of $\mathrm{SiCp} / \mathrm{Al}$ composites has fractal characteristics, such as self-similarity and self-affinity [12]. There are few publications focus on fractal investigation

\footnotetext{
${ }^{\mathrm{a}}$ Corresponding author : zhengwhit@gmail.com
} 
on surface of $\mathrm{SiCp} / \mathrm{Al}$ composites. So this paper presents a 3D fractal investigation on ultrasonic vibration assisted end grinding surface of $\mathrm{SiCp} / \mathrm{Al}$ composites to evaluate the effect pf process parameters, including cutting depth, feedrate, spindle speed and vibration amplitude, on the surface quality.

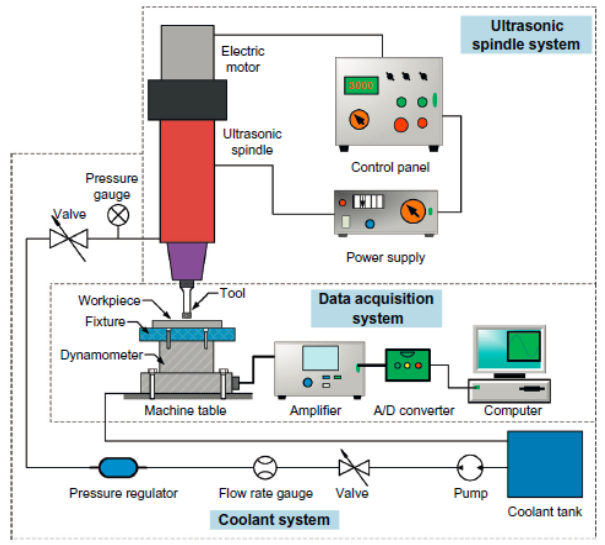

Figure. 1. Schematic diagram of ultrasonic vibration assisted end grinding.

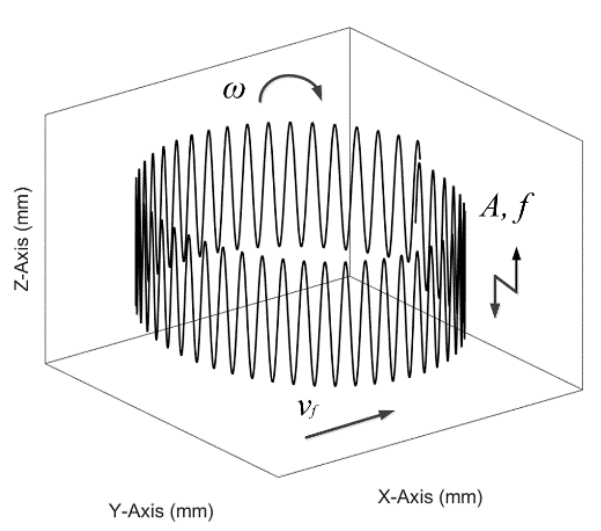

Figure. 2. The motion trajectory of grains in end surface of the grinding tool.

\section{Experimental setup and procedure}

\subsection{Experimental equipment}

Ultrasonic vibration assisted end grinding experiments were conducted on an ultrasonic vibration machine center (DMG Ultrasonic70-5 linear), which consisted of a numerical control system, an ultrasonic spindle system, a data acquisition system and a coolant system. The maximum spindle speed was 18000rpm. The frequency and amplitude supplied to the tool in the $\mathrm{z}$ direction were about $30 \mathrm{kHz}$ and $5 \mu \mathrm{m}$ respectively. The grinding tool with metal-bonded diamond abrasives was provided by SCHOTT Company, and its properties were listed in Table 1.

Table 1. Properties of the grinding tool used in experiments.

\begin{tabular}{cccc}
\hline $\begin{array}{c}\text { Abrasive size } \\
s(\mu \mathrm{m})\end{array}$ & Abrasive concentration & Outer radius & Inner radius \\
$R_{o}(\mathrm{~mm})$ & 30 & 20 \\
\hline 75 & 100 & $\mathrm{Ca}$ & $30 \mathrm{~mm})$ \\
\hline
\end{tabular}

\subsection{Workpiece material}




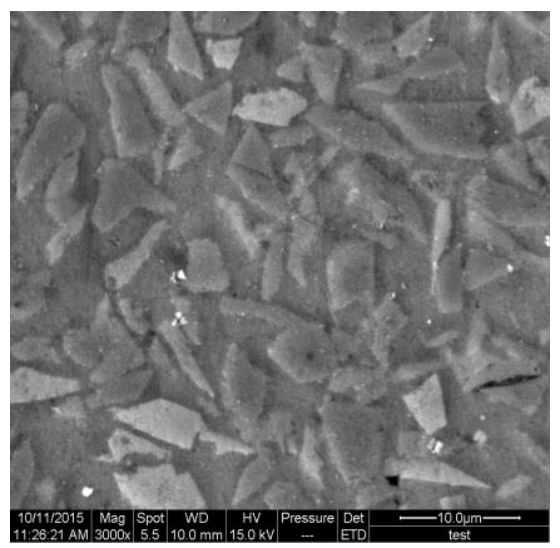

Figure. 3. The microstructure of the $\mathrm{SiCp} / \mathrm{Al}$ composites.

The workpiece material was $45 \% \mathrm{SiCp} / \mathrm{A} 12024$ composites. The average diameter of $\mathrm{SiC}$ particles was $5 \mu \mathrm{m}$. The microstructure and properties of the SiCp/Al composites were shown in Fig. 3 and Table 2 respectively.

Table 2. The properties of the $\mathrm{SiCp} / \mathrm{Al}$ composites.

\begin{tabular}{cc}
\hline Parameter & Value \\
\hline Modulus of elasticity $E(\mathrm{GPa})$ & 165 \\
Shear modulus $G(\mathrm{MPa})$ & 13.2 \\
Limit of yielding $\sigma_{s}(\mathrm{MPa})$ & 520 \\
Thermal conductivity $\beta(\mathrm{W} / \mathrm{m} . \mathrm{K})$ & 130 \\
Density $\rho\left(\mathrm{kg} / \mathrm{m}^{3}\right)$ & 2900 \\
Poisson ratio $\gamma$ & 0.26 \\
\hline
\end{tabular}

\subsection{Experiment}

Surface integrity was influenced by process parameters including spindle speed, feedrate, cutting depth and vibration amplitude. So single factor experiments based on four factors with five levels were conducted, as listed in Table 3. According to variational method, 3D surface fractal dimension was calculated with MATLAB software based on Profile data which was obtained by LCSM (laser confocal scanning microscope).

Table 3. Experimental parameters.

\begin{tabular}{ccccc}
\hline Levels & $\begin{array}{c}\text { Spindle speed } \\
n(\mathrm{rpm})\end{array}$ & $\begin{array}{c}\text { Feedrate } \\
v_{f}(\mathrm{~mm} / \mathrm{min})\end{array}$ & $\begin{array}{c}\text { Cutting depth } \\
a_{p}(\mu \mathrm{m})\end{array}$ & $\begin{array}{c}\text { Vibration amplitude } \\
A(\mu \mathrm{m})\end{array}$ \\
\hline 1 & 3000 & 5 & 5 & 0 \\
2 & 6000 & 10 & 10 & 1.25 \\
3 & 9000 & 15 & 15 & 2.5 \\
4 & 12000 & 20 & 20 & 3.75 \\
5 & 15000 & 25 & 25 & 5 \\
\hline
\end{tabular}

\section{Results and discussion}

Fig. 4 shows the influence of process parameters on 3D surface fractal dimension. It can be seen that with the variation of process parameters, 3D surface fractal dimension D is almost in the range of 2.62.75 , and nonlinearly increases with the spindle speed and vibration amplitude, and decreases with feedrate and cutting depth. Cutting depth and spindle speed have a large effect on the 3D surface fractal dimension compared with feed rate and vibration amplitude. 
Fig. 4(a) shows that when spindle speed is in the range of 3000-6000rpm, 3D surface fractal dimension increases drastically, however, when spindle speed is in the range of 6000-15000rpm, the variation rate of 3D surface fractal dimension is slowly. The typical 3D topographies of $\mathrm{SiCp} / \mathrm{Al}$ composite with two different spindle speed is shown in Fig. 5 (a) and (b), it can be seen that the surface quality generated with a large value of spindle speed $(15000 \mathrm{rpm})$ is superior to that generated with a small value of spindle speed (3000rpm).

Fig. 4(b) shows that 3D surface fractal dimension nearly linearly decreases with feedrate in the range of $5-25 \mathrm{~mm} / \mathrm{min}$. The typical 3D topographies of $\mathrm{SiCp} / \mathrm{Al}$ composite with two different feedrate is shown in Fig. 6 (a) and (b), it can be seen that the surface quality generated with a small value of feedrate $(5 \mathrm{~mm} / \mathrm{min})$ is superior to that generated with a large value of feedrate $(25 \mathrm{~mm} / \mathrm{min})$.

Fig. 4(c) shows that 3D surface fractal dimension nearly linearly decreases with cutting depth in the range of $5-20 \mu \mathrm{m}$, and decreases drastically with cutting depth in the range of $20-25 \mu \mathrm{m}$. The typical 3D topographies of $\mathrm{SiCp} / \mathrm{Al}$ composite with two different feedrate is shown in Fig. 7 (a) and (b), it can be seen that the surface quality generated with a small value of cutting depth $(5 \mu \mathrm{m})$ is superior to that generated with a large value of cutting depth $(25 \mathrm{~mm} / \mathrm{min})$.

Fig. 4(d) shows that 3D surface fractal dimension slowly increases with vibration amplitude in the range of $0-3.75 \mu \mathrm{m}$, and increases drastically in the range of $3.75-5 \mu \mathrm{m}$. The typical 3D topographies of $\mathrm{SiCp} / \mathrm{Al}$ composite with two different vibration amplitude is shown in Fig. 8 (a) and (b), it can be seen that the surface quality generated with a large value of vibration amplitude $(5 \mu \mathrm{m})$ is superior to that generated with a large value of vibration amplitude (0).

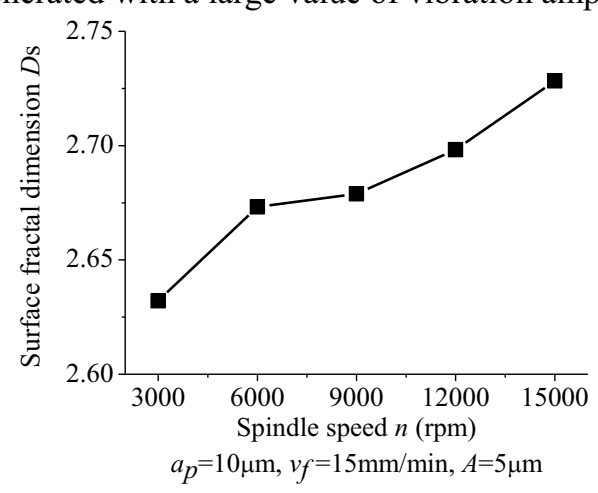

a

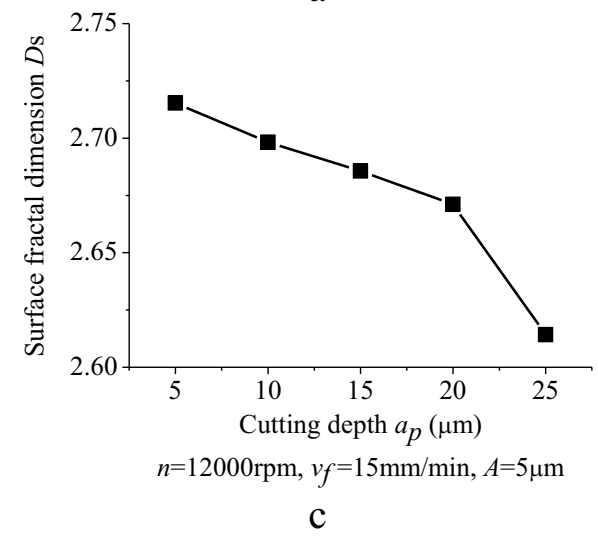

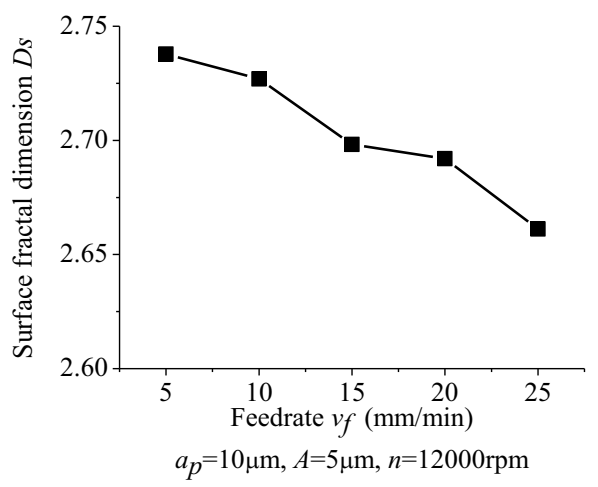

$\mathrm{b}$

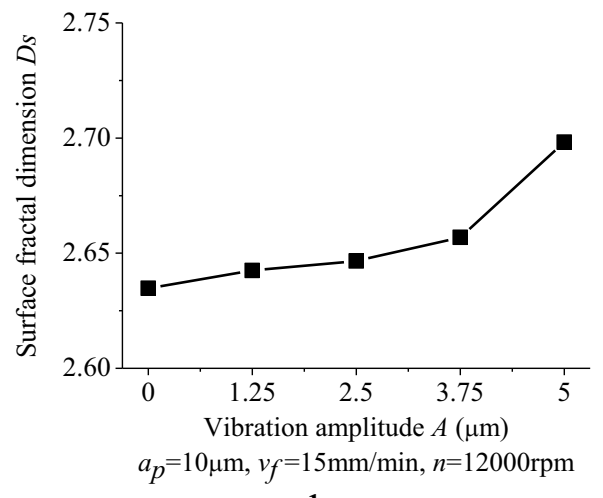

d

Figure. 4. The influence of process parameters on 3D surface fractal dimension. 


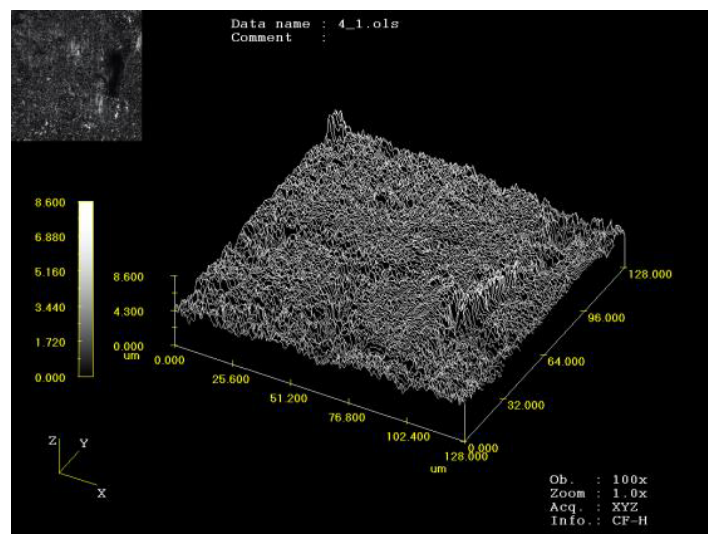

a) $n=3000 \mathrm{rpm}$

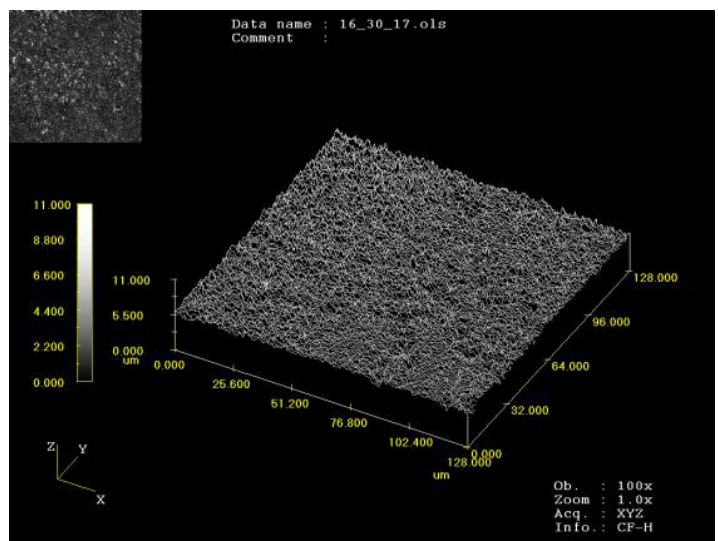

b) $n=15000 \mathrm{rpm}$

Figure. 5. 3D topographies of $\mathrm{SiCp} / \mathrm{Al}$ composites with different spindle speeds.

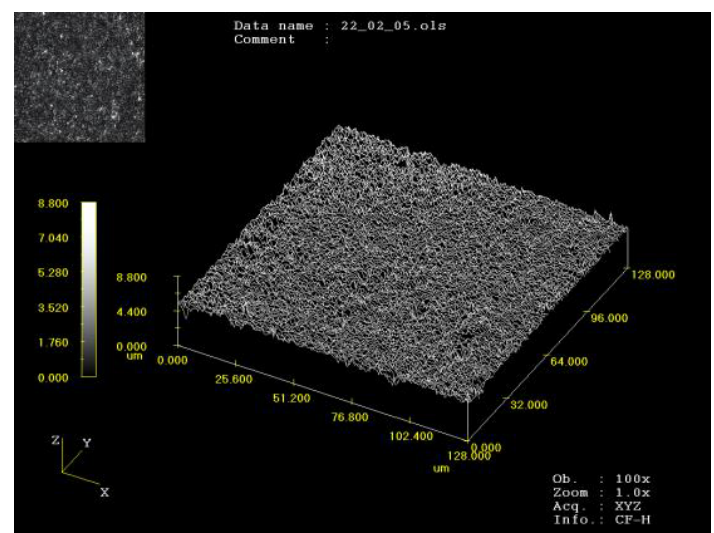

a) $v f=5 \mathrm{~mm} / \mathrm{min}$

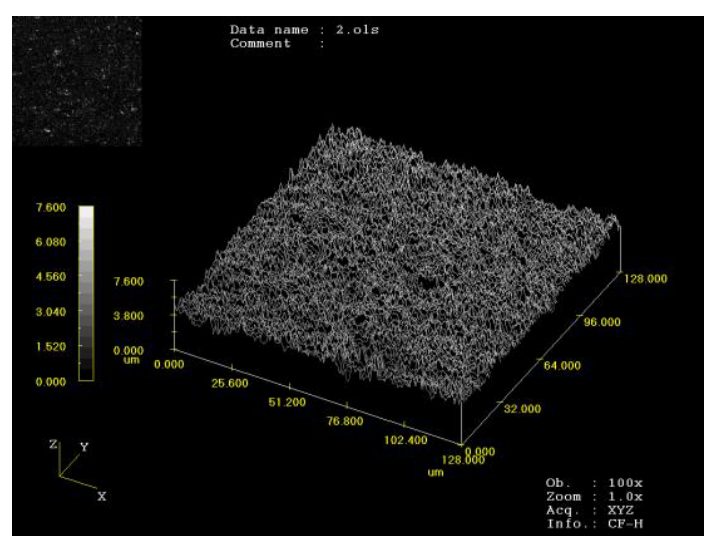

b) $v f=25 \mathrm{~mm} / \mathrm{min}$

Figure. 6. 3D topographies of $\mathrm{SiCp} / \mathrm{Al}$ composites with different feedrates.

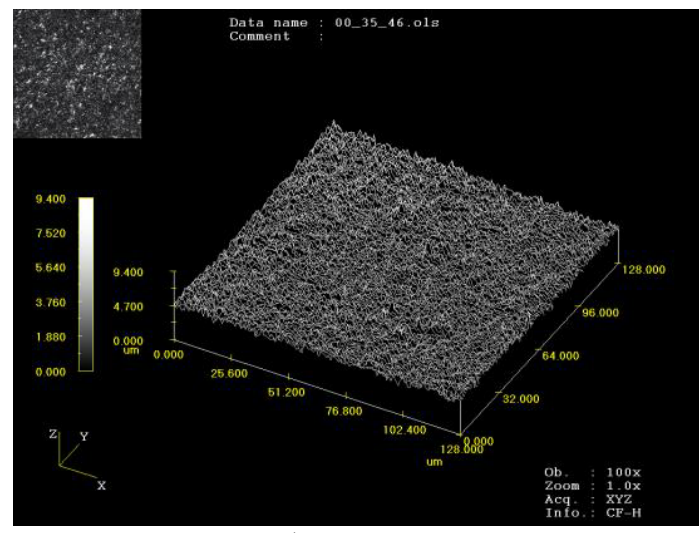

a) $a p=5 \mu \mathrm{m}$

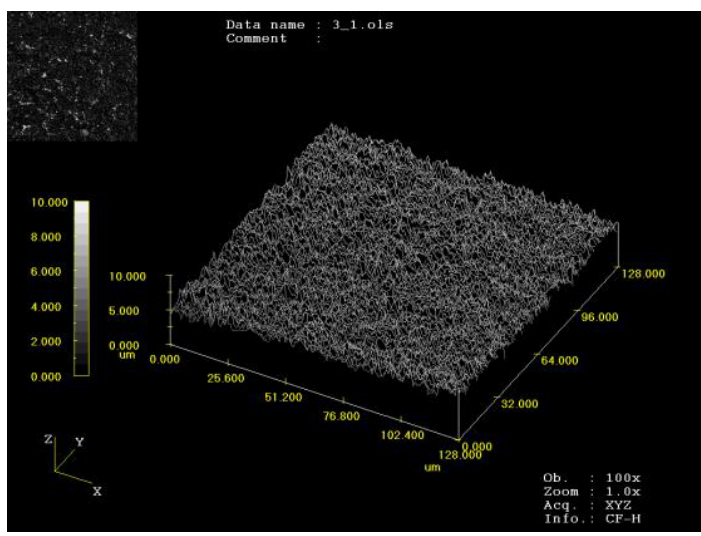

b) $a p=25 \mu \mathrm{m}$

Figure. 7. 3D topographies of $\mathrm{SiCp} / \mathrm{Al}$ composites with different cutting depths. 


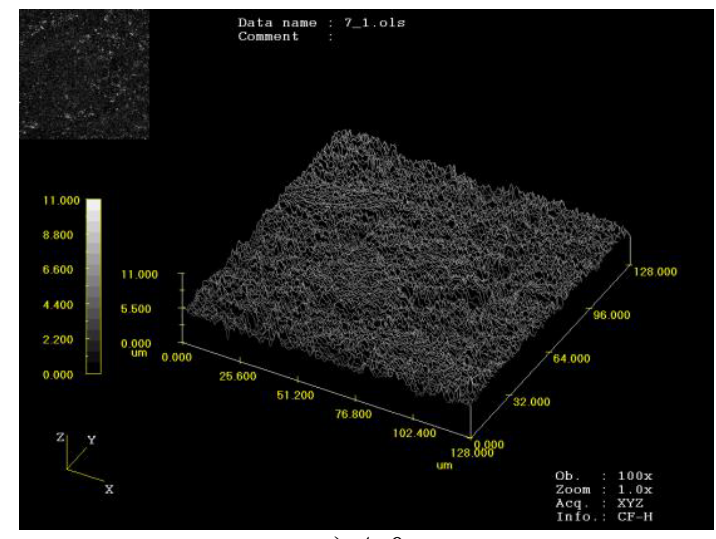

a) $A=0$

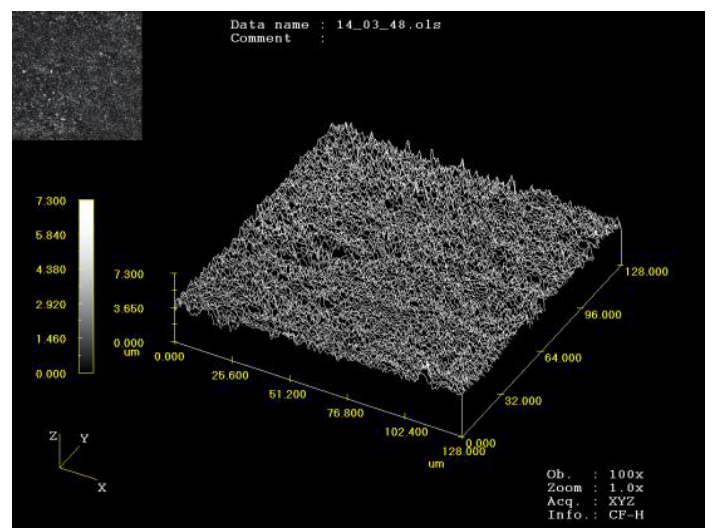

b) $A=5 \mu \mathrm{m}$

Figure. 8. 3D topographies of $\mathrm{SiCp} / \mathrm{Al}$ composites with different vibration amplitudes.

\section{Conclusion}

This paper presents a 3D fractal investigation on ultrasonic vibration assisted end grinding surface of $\mathrm{SiCp} / \mathrm{Al}$ composites. Several conclusions are obtained:

1 . With the variation of process parameters, 3D surface fractal dimension $D_{\mathrm{s}}$ is almost in the range of 2.6 2.75.

2. 3D surface fractal dimension $D_{\mathrm{s}}$ nonlinearly increases with an increase of the spindle speed and vibration amplitude, and decreases with an increase of feedrate and cutting depth.

3. Compared with feed rate and vibration amplitude, cutting depth and spindle speed have a large effect on the 3D surface fractal dimension $D_{\mathrm{s}}$.

4. A large value of 3D surface fractal dimension $D_{\mathrm{s}}$ corresponds to a better surface finish.

This work is supported by the National Natural Science Foundation of China (NSFC) (Grant No. 51375119).

\section{References}

1. A. Pramanik, L.C. Zhang, J.A. Arsecularatne,, Int. J. Mach. Tools Manuf. 48, 13 (2008)

2. W.L. Cong, Z.J. Pei, X. Sun, C.L. Zhang, Ultrasonics 54, 13 (2014)

3. S. Kannan, H.A. Kishawy, Int. J. Mach. Tools Manuf. 46 (2006)

4. U.A. Dabade, S.S. Joshi, R. Balasubramaniam, V.V. Bhanuprasad, J. Mater. Process. Technol. 192, 9 (2007)

5. K. Palanikumar, R. Karthikeyan, Mater. Des. 28, 9 (2007)

6. Y.F. Ge, J.H. Xu, H. Yang, S.B. Luo, Y. Fu, J. Mater. Process. Technol. 203, 10 (2008)

7. N.S.K. Reddy, S. Kwang-Sup, M.Y. Yang, J. Mater. Process. Technol. 201, 6 (2008)

8. R.K. Bhushan, S. Kumar, S. Das, Int. J. Adv. Manuf. Technol. 50, 11 (2010)

9. X.H. Shen, J.H. Zhang, D.L.X. Xing, Y.F. Zhao, Int. J. Adv. Manuf. Technol. 58, 9 (2012)

10. J.L. Jiang, P.Q. Ge, W.B. Bi, L. Zhang, D.X. Wang, Y. Zhang, Int. J. Mach. Tools Manuf. 74, 12 (2013)

11. T. Wang, L.J. Xie, X.B. Wang, T.Y. Shang, Def Technol 11, 6 (2015)

12. J.N. Muguthu, D. Gao, Mater. Manuf. Process. 28, 6 (2013) 